\title{
Grape polyphenols supplementation for exercise-induced oxidative stress
}

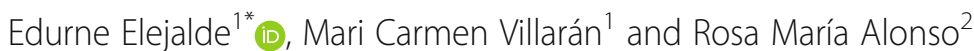

\begin{abstract}
Exercise induces free radicals' overproduction and therefore, an enhancement of oxidative stress, defined as an imbalance between the production of reactive species and the intrinsic antioxidant defense. Redox activity of reactive species plays an important and a positive role on exercise adaptation, but these species at very high concentrations have detrimental effects. As a result, the use of antioxidant supplements for reducing oxidative stress can be an effective health strategy to maintain an optimal antioxidant status. In this sense, grapes are an important source of natural antioxidants due to their high content in polyphenols. They have shown antioxidant potential benefits for the reduction of intense exercise effect in athletes of different sport disciplines. Consequently, it is plausible to hypothesize that a strategic supplementation with grape based products may be a good approach to mitigate the exercise induced oxidative stress. The goal of this review is to present the state of the art of supplementation effects with grape beverages and grape extracts on the oxidative stress markers in athletes. The data of polyphenolic dosages, participant characteristics and exercise protocols are reported.
\end{abstract}

Keywords: Grape, Polyphenols, Antioxidants, Supplementation, Sport, Exercise, Oxidative stress

\section{Background}

The World Health Organization defines physical activity as any bodily movement produced by skeletal muscles that requires energy expenditure. Regular physical activity has significant health benefits at all ages. Conversely, physical inactivity (insufficient physical activity) is one of the leading risk factors for noncommunicable diseases (NCD) and death worldwide [1].

The scientific evidence is strong regarding how a physically active lifestyle decreases oxidative stress (OS) [2]. This reduction may be one of the mechanisms responsible for an attenuated cellular aging [3], increased insulin sensitivity and lipid profile regulation [4], and reduced endothelial dysfunction [5]. In fact, oxidative stress status is generally found to be lower in athletes than in sedentary individuals.

\footnotetext{
* Correspondence: edurne.elejalde@tecnalia.com

${ }^{1}$ TECNALIA, Basque Research and Technology Alliance (BRTA), Parque

Tecnológico de Álava c/ Leonardo Da Vinci, 11, 01510 Miñano (Álava), Spain Full list of author information is available at the end of the article
}

Nevertheless, several studies have also suggested that acute and strenuous bouts of aerobic and anaerobic exercise induce the overproduction of free radicals and therefore, an enhancement of OS [6]. This effect varies according to the exercise mode, volume, intensity, training level, age, sex or nutritional status [6-9]. As a result, the use of supplements with antioxidant properties [10] for reducing the oxidative stress may be an effective health strategy.

In this sense, there is growing interest in the use of polyphenol-rich fruit and vegetables to mitigate exercise induced physiologic stress [11-13]. And grapes are an evident example of a fruit with a high content in polyphenols and with an evident nutritional value. Table 1 details the nutrients present in grapes.

Grapes are the fourth most produced fruit worldwide. The first place is for bananas with 115.75 million tonnes, followed by watermelons with 103.97 million tonnes and apples with 86.14 million tonnes [14]. The world production of grapes was 77.8 million tonnes in $2018,57 \%$

(c) The Author(s). 2021 Open Access This article is licensed under a Creative Commons Attribution 4.0 International License, which permits use, sharing, adaptation, distribution and reproduction in any medium or format, as long as you give appropriate credit to the original author(s) and the source, provide a link to the Creative Commons licence, and indicate if changes were made. The images or other third party material in this article are included in the article's Creative Commons licence, unless indicated otherwise in a credit line to the material. If material is not included in the article's Creative Commons licence and your intended use is not permitted by statutory regulation or exceeds the permitted use, you will need to obtain permission directly from the copyright holder. To view a copy of this licence, visit http://creativecommons.org/licenses/by/4.0/ The Creative Commons Public Domain Dedication waiver (http://creativecommons.org/publicdomain/zero/1.0/) applies to the data made available in this article, unless otherwise stated in a credit line to the data. 
Table 1 Essential nutrients in $100 \mathrm{~g}$ of grapes

\begin{tabular}{|c|c|c|}
\hline Nutrient $^{\mathrm{a}}$ & Amount & Unit \\
\hline Water & 80.54 & $g$ \\
\hline Energy & 69 & kcal \\
\hline Protein & 0.72 & g \\
\hline Total lipid (fat) & 0.16 & g \\
\hline Carbohydrate & 18.1 & g \\
\hline Fiber, total dietary & 0.9 & g \\
\hline Sugars, total & 15.48 & $g$ \\
\hline \multicolumn{3}{|l|}{ Minerals } \\
\hline Calcium, Ca & 10 & mg \\
\hline Iron, Fe & 0.36 & mg \\
\hline Magnesium, Mg & 7 & mg \\
\hline Phosphorus, P & 20 & mg \\
\hline Potassium, K & 191 & mg \\
\hline Sodium, $\mathrm{Na}$ & 2 & mg \\
\hline Zinc, Zn & 0.07 & mg \\
\hline Copper, Cu & 0.127 & mg \\
\hline Selenium, Se & 0.1 & mg \\
\hline \multicolumn{3}{|l|}{ Vitamins } \\
\hline Vitamin A & 3 & $\mu g$ \\
\hline Thiamin, Vitamin B1 & 0.069 & mg \\
\hline Rivoflavin, Vitamin B2 & 0.07 & mg \\
\hline Niacin, Vitamin B3 & 0.188 & mg \\
\hline Pyridoxine, Vitamin B6 & 0.086 & mg \\
\hline Folate, Vitamin B9 & 2 & $\mu \mathrm{g}$ \\
\hline Cyano-cobalamin, Vitamin B12 & 0 & $\mu g$ \\
\hline Vitamin C & 3.2 & mg \\
\hline Vitamin $\mathrm{E}$ & 0.19 & mg \\
\hline Vitamin $\mathrm{K}$ & 14.6 & $\mu \mathrm{g}$ \\
\hline \multicolumn{3}{|l|}{ Phytonutrients } \\
\hline Carotene, alpha & 1 & $\mu \mathrm{g}$ \\
\hline Carotene, beta & 39 & $\mu g$ \\
\hline Lutein-zeaxanthin & 72 & $\mu \mathrm{g}$ \\
\hline Polyphenols, total (black) ${ }^{b}$ & 184.97 & mg \\
\hline Polyphenols, total (green) ${ }^{c}$ & 121.80 & mg \\
\hline
\end{tabular}

${ }^{a}$ Data from USDA Nutrient Data Laboratory

b, c Data from Phenol-Explorer 3.0 database

of wine grape, $36 \%$ of table grape and $7 \%$ of dried grape [15]. However, considering that fresh grapes might not be available everywhere during the whole year, natural supplements obtained from grapes, such as grape beverages or grape extracts may be an interesting alternative to fresh fruit.

Fruit polyphenols have shown antioxidant potential beneficial for the reduction of the effects of oxidative damage during intense exercise in athletes of different disciplines [16, 17]. Polyphenols are poorly absorbed in the human small intestine and undergo extensive biotransformation after ingestion [18, 19]. Evidence supports that biological activities of many polyphenols are actually improved after their biotransformation [20-22]. This process takes time, hence, a prolonged period of polyphenol intake is recommended prior to exercise stress interventions to allow body tissues to adapt to a higher phenolic flux level. That is the reason besides using appropriate outcome measures, long periods are needed to capture such bioactivities [23]. In this context, targeted metabolomics is a suited tool that allows to investigate the shifts of gut-derived metabolites after polyphenol supplementation. Several human trials are revealing an increasing number of metabolites that appear at high concentration levels in the colon and systemic circulation which could be directly associated with polyphenols positive effect against OS [23, 24]. In fact, a systematic review suggested the key role of gut microbiota in controlling the OS during intense exercise [25].

Currently, few papers are available and research designs vary widely regarding to grape polyphenolic supplementation form (drinkable or edible), dosage (acute to multiple weeks and months), type of exercise stress (acute or chronic), profile of subject (trained or untrained), and oxidative stress outcome measures. The aim of this review is to examine the potential effect of these dietary supplements on oxidative stress promoted by exercise in athletes/trained subjects. For this purpose, an evaluation of the available scientific literature has been carried out since it is an important step to determine the efficacy of these polyphenolic based products on the redox status of the athletes. A "dietary supplement" has been considered as a product that is intended to supplement the diet and contains a "dietary ingredient" [26]. In this work, the ingredient refers to the polyphenols present in the grape-based products studied.

\section{Exercise-induced oxidative stress}

Oxidative stress is defined as a result of an imbalance between reactive species production and intrinsic antioxidant defense [27]. For example, athletes participating in one bout of prolonged and intensive exercise such as marathon and ultramarathon race event show acute physiological stress reflected by muscle microtrauma, oxidative stress, inflammation, and gastrointestinal dysfunction [11, 23, 24, 28-34].

The discovery that muscular exercise increases oxidant damage did not occur until the late 1970s [35-37]. Although the biological significance of this finding was unclear, these pioneering studies generated interest for future investigations to examine the important role that radicals, reactive nitrogen species (RNS), and reactive oxygen species (ROS) play in skeletal muscle and other 
metabolically active organs during exercise. Indeed, growing evidence reveals that while uncontrolled production of RNS and ROS can damage cells, intracellular oxidants also play important regulatory roles in the modulation of skeletal muscle force production, regulation of cell signaling pathways, and control of gene expression [35, 38-42].

Although a multitude of free radicals exists, those derived from either oxygen and/or nitrogen represent the most important class of radicals generated in living systems [43, 44]. The radicals themselves as well as the nonradical species created via interaction with free radicals are collectively referred to as reactive oxygen/nitrogen species (RONS) [45].

The redox activity of RONS plays a critical role in cell signaling and exercise adaptation. It is a phenomenon widely known as hormesis, which means that low levels of stress promote adaptation and therefore, protection from subsequent stress [46, 47]. Exercise-induced RONS act as signaling molecules for the beneficial effects in response to exercise training. RONS produced during muscle contractions are responsible for key adaptations to exercise training as mitochondrial biogenesis [48], endogenous antioxidant enzyme upregulation [49], muscle hypertrophy [50] and glucose uptake by the skeletal muscle [51].

However, at very high concentrations, free radicals instead of being advantageous they can have detrimental effects [46]. During heavy endurance training, endogenous antioxidant capacity cannot counteract the increasingly high RONS generation, resulting in a state of OS and subsequent cellular damage [52].

OS can be basically estimated measuring free radicals, radical mediated damages on lipids, proteins or deoxyribonucleic acid (DNA) molecules and performing the total antioxidant capacity.

The results of free radicals must be interpreted with caution because of the short life of the ROS, their strong ability to react and their low concentration.

Regarding lipid peroxidation, the conventional oxidative stress marker is malondialdehyde (MDA) which is produced during fatty acid oxidation. This product is measured by its reaction with thiobarbituric acid which generates thiobarbituric acid reactive substances (TBARS) in blood samples. F2-isoprostanes are also analyzed to estimate the damage on lipids. They are produced by non-cyclooxygenase dependent peroxidation of arachidonic acid. They are stable products released into circulation before the hydrolyzed form is excreted in urine. Different methodologies can be used for their analysis such as Gas chromatography-Mass Spectrometry (GC-MS), High Performance Liquid Chromatography/ Gas Chromatography-Mass Spectrometry (HPLC/GCMS), Gas Chromatography-tandem Mass Spectrometry
(GC-tandem MS), and more recently some immunoassay techniques [53].

Free radical induced modification of proteins causes the formation of carbonyl groups into amino acid side chains. An increase of carbonyls is linked to oxidative stress in blood samples.

For DNA modification quantification, the most used marker is the nucleotide 8-hydroxy-2'-deoxyguanosine (8-OHdG), excreted via blood and urine which is produced by free radicals-induced guanine oxidation and analyzed by Enzyme-Linked ImmunoSorbent Assay (ELISA assays), High Performance Liquid ChromatographyElectrochemical Detection HPLC-ECD or HPLC/GC-MS methods [53].

Regarding total antioxidant capacity, is commonly assessed via the application of one of several antioxidant capacity assays: trolox equivalent antioxidant capacity (TEAC assay), ferric reducing ability of plasma (FRAP assay), 2,2-diphenyl-1-picrylhydrazyl (DPPH assay) and oxygen radical absorbance capacity (ORAC) and/or measurement of changes in specific antioxidant enzymatic activity like superoxide dismutase (SOD), catalase (CAT) and glutathione peroxidase (GPX) by enzymatic assays.

The use of antioxidant supplements for ameliorating the exercise-induced RONS has become a current topic as there is considerable evidence that these supplements might not only prevent the toxic effects of RONS, but also blunt their signaling properties responsible for the adaptive responses [54]. While chronic daily use of antioxidant supplements should be avoided, strategic use of these products in and around periods of heavy training/ game scheduling is the best approach [55]. Anyway, further research to observe effects of nutritional antioxidant supplements on exercise-induced oxidative stress must be performed [56].

\section{Polyphenols: a natural source of antioxidants}

An antioxidant can be defined as a substance that helps to reduce the severity of OS either by forming a less active radical or by quenching the damaging free radicals chain reaction on substrates such as proteins, lipids, carbohydrates or DNA [57]. Some antioxidants can interact with other antioxidants regenerating their original properties; this mechanism is usually referred to as the "antioxidant network".

The antioxidants can be endogenous or obtained exogenously as a part of a diet or as a dietary supplement. Some dietary compounds that do not neutralize free radicals but enhance endogenous antioxidant activity may also be classified as antioxidants. While exogenous antioxidant may attenuate intracellular adaptation in response to exercise training, there is no literature to suggest that increasing endogenous antioxidants has this effect [46]. 
Endogenous antioxidants keep optimal cellular functions and thus systemic health and well-being. However, under some conditions endogenous antioxidants may not be enough, and extra antioxidants may be required to maintain optimal cellular functions. Such a deficit is evident in some individuals during the overloaded period of training or in circumstances where athletes have little time for recovery like in tournament situations. However, available data still do not allow to define the optimal antioxidant intake that would protect overloaded or, even more so, overtrained individuals [58].

Humans have developed highly complex antioxidant systems (enzymatic and non-enzymatic) which work synergistically and together with each other to protect the cells and organ systems of the body against free radical damage.

The most efficient enzymatic antioxidants are superoxide dismutase (SOD), catalase (CAT) and glutathione peroxidase (GPX). In Fig. 1, the antioxidant enzyme system in the cell is shown.

SOD is the major defense upon superoxide radicals and is the first barrier protection against oxidative stress in the cell. SOD represents a group of enzymes that catalyse the dismutation of $\mathrm{O}_{2}{ }^{--}$and the formation of hydrogen peroxide $\left(\mathrm{H}_{2} \mathrm{O}_{2}\right)$. Manganese $(\mathrm{Mn})$ is a cofactor of $\mathrm{Mn}-\mathrm{SOD}$ form, present in the mitochondria and copper $(\mathrm{Cu})$ and zinc $(\mathrm{Zn})$, are cofactors present in cytosol [57]. In muscular cells, $65-85 \%$ of SOD activity is done in the cytosol [59]. Furthermore, CAT is responsible of the decomposition of $\mathrm{H}_{2} \mathrm{O}_{2}$ to form water $\left(\mathrm{H}_{2} \mathrm{O}\right)$ and oxygen $\left(\mathrm{O}_{2}\right)$ in the cell. This antioxidative enzyme is widely distributed in the cell, with the majority of the activity occurring in the mitochondria and peroxisomes
[59]. With high ROS concentration and an increase in oxygen consumption during exercise, the enzyme GPX, present in cell cytosol and mitochondria, is activated to remove hydrogen peroxide from the cell [60]. The reaction uses reduced glutathione (GSH) and transforms it into oxidized glutathione (GSSG). GPX and CAT have the same action upon $\mathrm{H}_{2} \mathrm{O}_{2}$, but GPX is more efficient with high ROS concentration and CAT with lower $\mathrm{H}_{2} \mathrm{O}_{2}$ concentration [61, 62]. In response to increased RONS production the antioxidant defense system may be reduced temporarily, but may increase during the recovery period $[63,64]$ although conflicting findings have been reported [65]. GPX requires several secondary enzymes glutathione reductase (GR) and glucose-6-phosphate dehydrogenase (G-6-PDH) and cofactors GSH and the reduced nicotinamide adenine dinucleotide phosphate (NADPH) to remove $\mathrm{H}_{2} \mathrm{O}_{2}$ from the cell.

By contrast, non-enzymatic antioxidants include vitamin A (retinol) [57], vitamin E (tocopherol) [66], vitamin $\mathrm{C}$ (ascorbic acid), thiol antioxidants (glutathione, thioredoxin and lipoic acid), melatonin, carotenoids, micronutrients (iron, copper, zinc, selenium, manganese) which act as enzymatic cofactors and flavonoids, a specific group of polyphenols [67].

Among non-enzymatic antioxidants, polyphenols are a group of phytochemicals that have received great attention of researchers in the last years considering their beneficial effects in the prevention of many chronic diseases $[68,69]$. They constitute one of the most numerous and widely distributed groups of natural products in the plant kingdom. Polyphenols can be classified by their origin, biological function, and chemical structure. More than 8000 phenolic structures are currently known, and

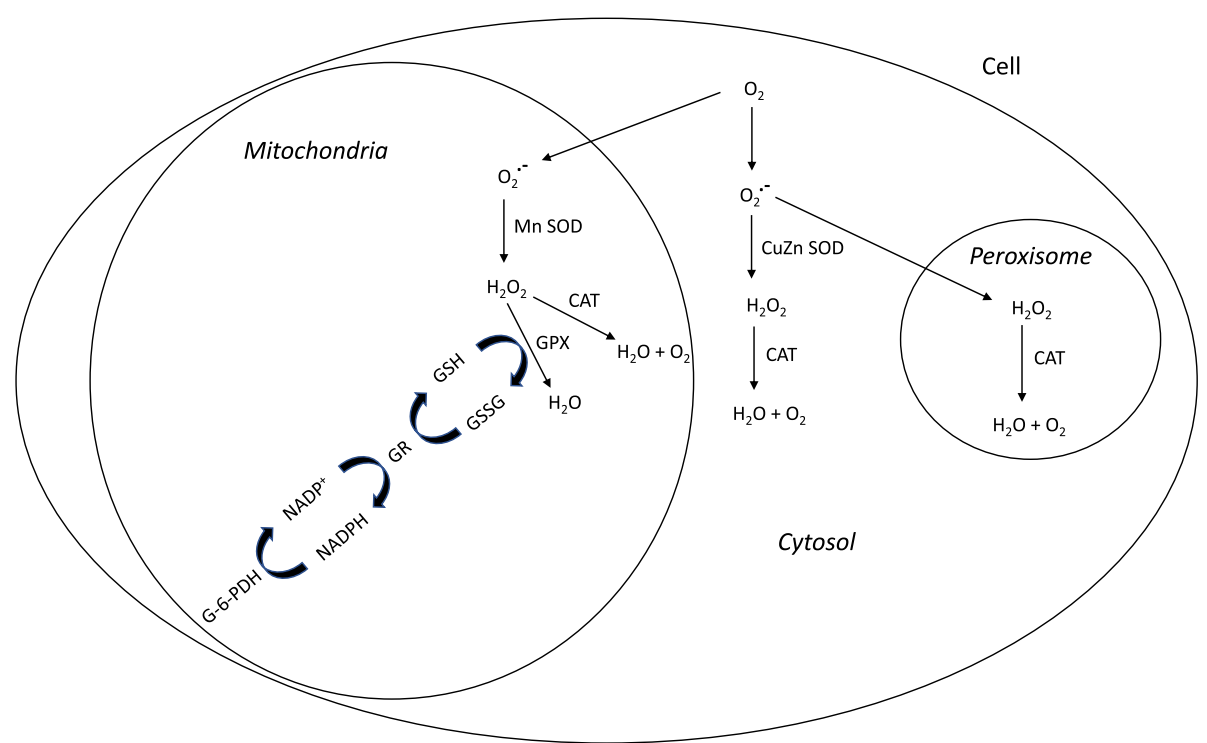

Fig. 1 The antioxidant enzyme system in the cell 
among them over 4000 flavonoids have been identified [70-72]. The major groups of flavonoids of nutritional interest are the flavonols, the flavones, the flavanols, the flavanones, the anthocyanidins and the isoflavones [73]. See Fig. 2.

Polyphenols have showed to act as a defense against OS caused by excess reactive oxygen species (ROS) [74]. Their potential health benefits as antioxidants is mediated by their functional hydroxyl groups $(\mathrm{OH})$ that determine the ROS synthesis suppression, the chelation of trace elements responsible for free radical generation, the scavenging ROS and the improvement of antioxidant defenses [75, 76].

Commonly, grapes and grape based products are recognized as natural food products with strong antioxidant activity precisely due to their high content in polyphenolic compounds [77].

In fact, some nutraceuticals based on polyphenols have already showed efficacy in reducing the oxidized lowdensity lipoprotein levels and trimethylamine $\mathrm{N}$-oxide (TMAO is a recognized biomarker of increased cardiovascular risk) serum levels in overweight/obese adults [78] and the gut microbiota remodeling [79]. At the same time, these products have also demonstrated a reduced OS and the oxidative damage at muscular level and improved the muscle performance but in aged rats [80].

Table 2 provides a summary of the different polyphenol families found in grapes.

Considering their polyphenolic composition, it is plausible to hypothesize that the strategic supplementation with grape based products may have a positive antioxidant effect in athletes in particular situations. However, pilot studies on the antioxidant capacity of grapes and grape based products with athletes are scarce. Few studies are focused on the consumption of antioxidant supplements obtained from grape based products to reduce the immediate increase of oxidative stress biomarkers.

Table 3 shows a descriptive summary of 12 studies published since 2005 that investigate the effect of supplementation with grape based products on exerciseinduced oxidative stress markers and the antioxidant enzymatic system efficiency. The studies collected in Table 3 fulfill the following inclusion criteria: (i) pilot studies conducted with healthy human participants (active or trained subjects), (ii) original studies with an acute or long-term grape supplementation intervention on physiological responses associated with OS produced by exercise, (iii) published until June 2020. Exclusion criteria are animal studies and studies in which no exercise is performed. Wine may be a good option as a product obtained from grapes with an important source of phenolic compounds. However, considering that wine contains alcohol may not be an option for all consumers due to certain disease conditions, religious restrictions, or age, it has not been considered.

\section{Grape polyphenols supplementation effect}

Among the studies found, six of the products are beverages made with grape and the rest are grape extracts and only one is referred to dried grapes.

\section{Grape beverage supplements}

Within the beverages, one is a grape beverage but mixed with raspberry and red currant [81], another one a grape beverage specified as organic [82], two of them are grape concentrate drinks $[83,84]$ and the last two a purple grape juice [85].

Regarding the polyphenolic content, the studies show a wide number of dosages. Morillas-Ruiz et al.dose range. [81] established an acute dose of the beverage at<smiles></smiles><smiles>[R]c1cc(-c2cc(=O)c3c(O)cc(O)cc3o2)ccc1O</smiles><smiles>[Y9]c1cc(C2Oc3cc(O)cc(O)c3CC([Y9])C2c2cc(O)c(O)c(O)c2)cc(O)c1O</smiles>

Flavan-3-ol

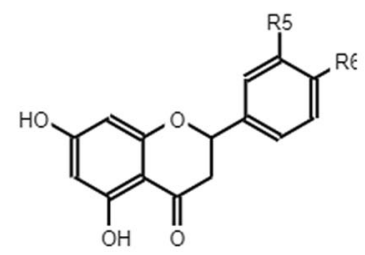

Flavanone<smiles></smiles>

Anthocyanidin

Fig. 2 Flavonoid structures. $\mathrm{R} 1=\mathrm{OH}$ : Quercetin; $\mathrm{R} 1=\mathrm{H}$ : Kaempferol; $\mathrm{R} 2=\mathrm{OH}$ : Luteolin; $\mathrm{R} 3=\mathrm{OH}, \mathrm{R} 4=\mathrm{H}$ : $\mathrm{Catechin}$; $\mathrm{R} 3=\mathrm{gallate}$, $\mathrm{R} 4=\mathrm{OH}$ : Epigallocatechin-3-gallate; $\mathrm{R} 5=\mathrm{OH}, \mathrm{R} 6=\mathrm{OH}$ : Eriodictyol; R5 = H, R6 = OH: Naringenin; R7 =OH, R8= H: Cyanidin, R7 = OCH , R8 = OCH3: Malvidin 
Table 2 Classification of major polyphenols present in grapes and derivatives

\begin{tabular}{lll}
\hline Group & Subclass & Compound \\
\hline Flavonoids & Flavonols & Quercetin, Kaempferol, Myricetin, Isorhamnetin, Laricitrin, Syringetin \\
& Flavones & Luteolin, Genistein, Apigenin \\
& Flavanols & Catechin, Epicatechin, Gallocatechin, Epigallocatechin, Epicatechin \\
glallate, Epigallocatechin gallate & Eriodictyol, Naringenin, Hesperetin
\end{tabular}

$30 \mathrm{ml} / \mathrm{kg}$ before doing exercise and $30 \mathrm{ml} / \mathrm{kg}$ every 15 min during $90 \mathrm{~min}$ of constant-load test on a bicycle ergometer. Considering the total phenolic content of $1.41 \mathrm{mg} / \mathrm{l}$ of the beverage, this means a total polyphenolic dose of $17.76 \mathrm{mg}$ for a moderate trained cyclist with $70 \mathrm{~kg}$ for example. In this study no significant difference from basal to post-exercise period was detected for plasma thiobarbituric acid reactive substances analysis (TBARS) neither in the placebo group $(n=13)$ nor the group receiving the antioxidant supplemented beverage $(n=13)$. This could be explained by a not high enough intensity exercise to alter the redox state or by the adaptation on antioxidant defenses in well-trained subjects. However, the antioxidant supplementation had a beneficial effect on the oxidation of proteins induced by exercise and reduced this index. In fact, the group receiving antioxidants obtained a $29 \%$ reduction in protein carbonyls. However, an unexpected result was obtained for 8-oxo-7,8-dihydro-2' deoxyguanosine (8-OHdG) in urine with a greater decrease in comparison to the study group. Despite these results, the authors defend the usefulness of $8-\mathrm{OHdG}$ determination as a sensitive index of the relationship between exercise and oxidative stress and demonstrate that antioxidant-supplemented beverages reduce $8-\mathrm{OHdG}$ excretion following a $90 \mathrm{~min}$ exercise protocol.

Other authors established an intake of $300 \mathrm{ml} /$ day of an organic grape juice for 20 days [82]. Considering the total phenolic content of $5.32 \mathrm{mg} / \mathrm{ml}$, the total ingestion of polyphenols per day was $1.59 \mathrm{~g}$ for each trained male triathlete $(n=10)$. In this case, the results showed a decreased superoxidase dismutase (SOD) activity in erythrocytes activity after 20 days. SOD is a cytosolic antioxidant enzyme responsible for superoxide anion radical dismutation into oxygen and hydrogen peroxide and is sensitive to the intake of polyphenols in humans. The reduction before (baseline) and after 20 days was $27.8 \pm 6.3$ to $24.3 \pm 2.5 \mathrm{U} / \mathrm{mg}$ protein. The authors attributed this decrease to the reduction of intra- and extracellular oxidative imbalances.

The effect of the same volume of $300 \mathrm{ml} /$ day of a grape concentrate juice (Vitis labrusca) with a total phenolic content of $45.8 \mathrm{~g}$ GAE (Gallic Acid Equivalents) $/ \mathrm{kg}$ beverage was studied by Silvestre et al. [83]. In this case, the total intake of polyphenols for each trained triathlete $(n=6)$ was $3 \mathrm{~g}$. The acute intake was in two equal doses before and after the training. The results showed a significant increase in SOD in the blood samples regardless of the drink consumed (grape drink or placebo). A lower increase in reduced glutathione (GSH) levels in the test group in comparison to the placebo group was obtained. This result may indicate a lower oxidation of GSH to GSSG, oxidized glutathione, due to the action of glutathione peroxidase (GPX) or even more efficient synthesis by glutathione reductase. Besides, higher values in TBARS value with placebo in comparison to the grape concentrate drink were obtained just after the exercise and after one hour. This means a lower value in this oxidative stress marker related to lipid peroxidation when grape concentrate drink is consumed. 


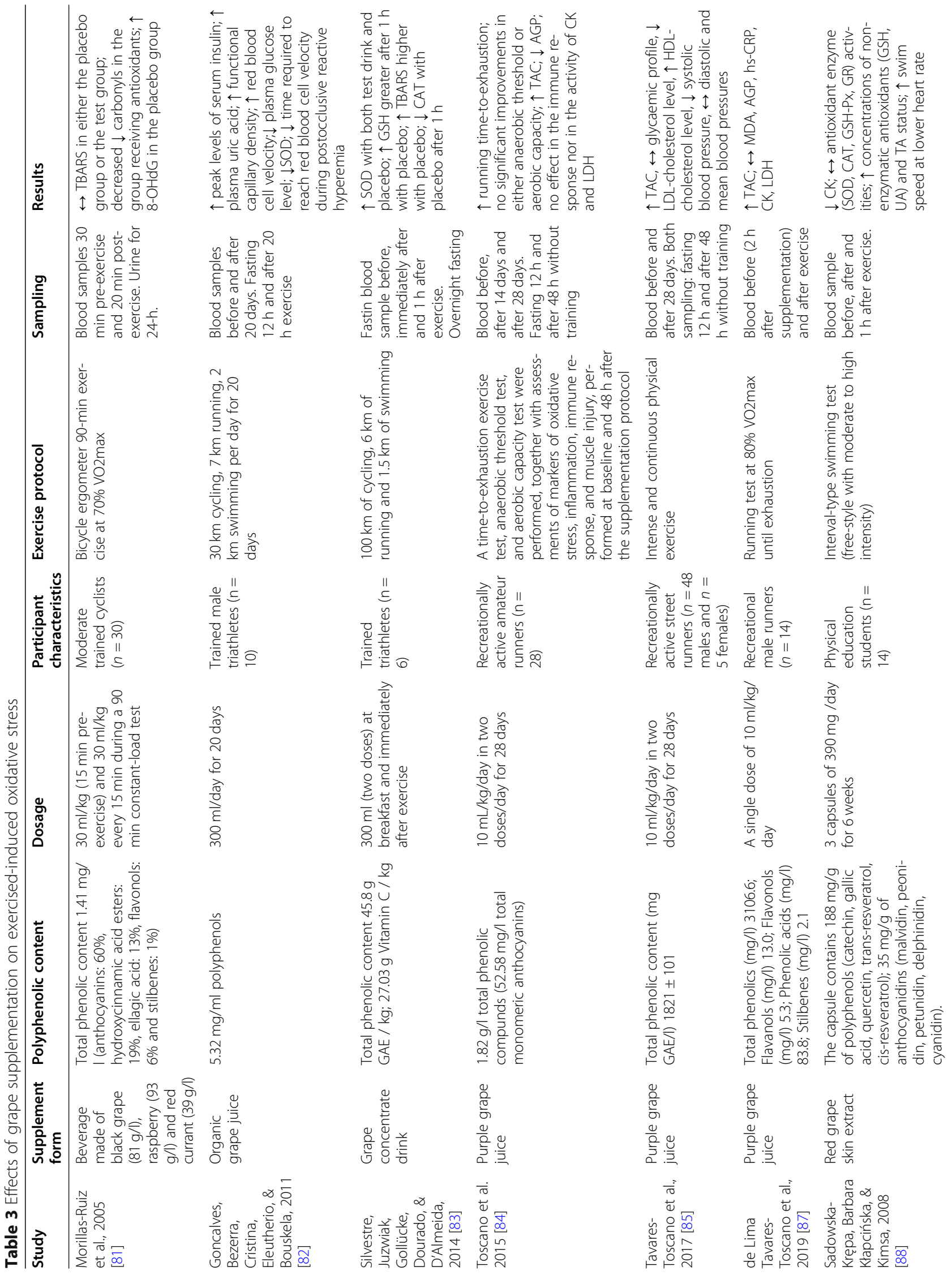




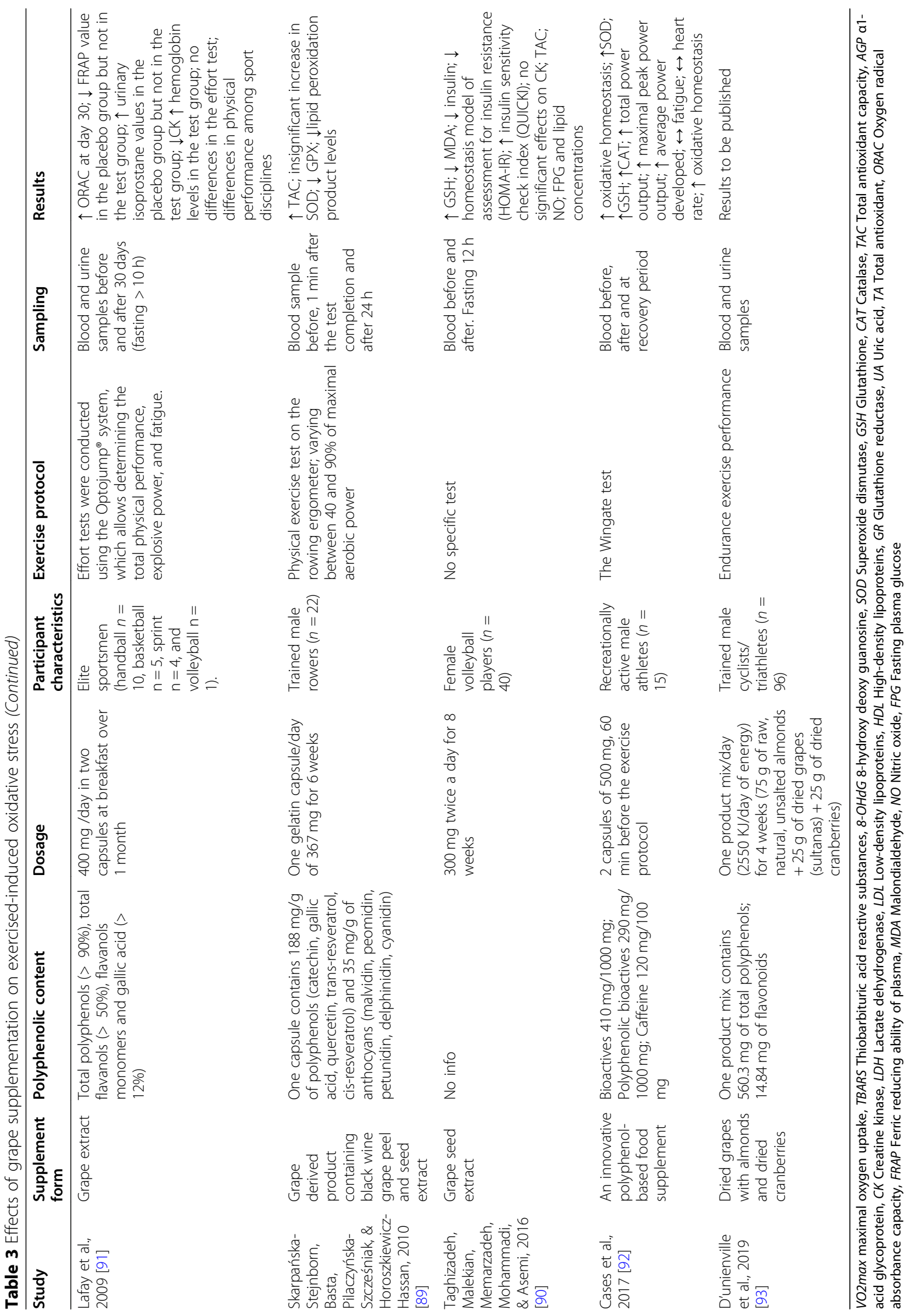


But the antioxidant enzyme catalase (CAT) activity remained stable in the group that consumed the beverage. The authors suggest that the studies on the CAT response to exercise have shown conflicting results especially to a single exercise session. The study concludes that TBARS, $\mathrm{CAT}$ and GSH values suggest that this grape concentrate drink presents potential to modulate exercise-induced oxidative stress.

In another study Tavares-Toscano et al. [85] provided purple grape juice to recreationally active street runners $(n=53)$ at a total dose of $10 \mathrm{ml} / \mathrm{kg} /$ day for 28 days. Considering the total phenolic content of $1821 \pm 101 \mathrm{mg}$ GAE/l the total intake of polyphenols reached the total of $1.27 \mathrm{~g}$ per day and $35.69 \mathrm{~g}$ polyphenols after 28 days. The results showed a significant increase, up to $39 \%$ in the plasma antioxidant activity after 28 days. In this case the total antioxidant capacity (TAC) was evaluated in the plasma by evaluating the radical scavenging according to the $\alpha, \alpha$-diphenyl- $\beta$-picrylhydrazyl (DPPH) method. This analytical method is used to determine the TAC of a compound, an extract or other biological sources by using a stable free radical DPPH. The assay is based on the measurement of the scavenging capacity of antioxidants towards it [86]. The authors showed a deep characterization of the grape juice. They did not analyze any oxidative stress markers, but showed an increase in high density lipoprotein-cholesterol (HDL-cholesterol) fraction and a decreased low-density lipoprotein-cholesterol (LDL-cholesterol) fraction demonstrating that grape juice may enhance the benefits of physical training,

The same author [84] demonstrated, with the same beverage and dosage in recreationally active amateur runners $(n=28)$, an increase in TAC by $38 \%$ in comparison to the control group after 28 days. Besides the malondialdehyde (MDA) data indicated that grape juice supplementation did not prevent lipid peroxidation in athletes, but the increase was lower than in the group with no grape juice.

Tavares-Tocano et al. [87] also showed that a single dose of purple grape juice of $10 \mathrm{ml} / \mathrm{kg}$ with a concentration of $3106.6 \mathrm{mg} / \mathrm{l}$ was able to promote increased plasma antioxidant activity in recreational male runners, but did not change the plasma concentration of lipid peroxidation by MDA.

\section{Grape extract supplements}

Studies found with this type of supplements are focused on an extract obtained from the grape' skin [88], extracts obtained from grape seeds [89, 90], the whole grape [91], an innovative polyphenol-based food supplement based on a grape extract [92] and dried grapes with almonds and dried cranberries [93].

Concerning the edible grape products, to the best of our knowledge the first study that analyzed the effect of grape polyphenols supplementation on the blood antioxidant status was in 2008 [88]. In this study an intake of 3 capsules containing $390 \mathrm{mg}$ of red grape skin extract per day for 6 weeks to fourteen physical education students $(n=14)$ was established. This dosage means $0.22 \mathrm{~g}$ polyphenols per day and a total $9.24 \mathrm{~g}$ after the 6 weeks. The results showed an insignificant modification of antioxidant enzyme: SOD, CAT, GSH and glutathione reductase (GR) activities, concentrations of non-enzymatic antioxidants: GSH and uric acid (UA) and total antioxidant status (TAS). However, the authors indicated that the supplementation with the alcohol-free red wine grape polyphenolic extract might influence the attenuation of the post-exercise release creatine kinase (CK) into the blood.

Lafay et al. [91] established a dosage of $400 \mathrm{mg}$ of a commercial grape extract over a month period for elite sportsmen $(n=20)$. In this case, no information regarding the total polyphenolic content was given. The authors showed that consumption of grape extract standardized in flavanols permits to ameliorate the oxidative stress/antioxidant status balance in elite athletes during a competition period, and to enhance physical performance in one category of sportsmen (handball). Besides the administration of grape extract decreased the plasma $\mathrm{CK}$ concentration and increased the hemoglobin $(\mathrm{Hb})$ level in plasma suggesting a protection of cells against oxidative stress damage.

In another work [86] the authors gave to each male rower $(n=22)$ one gelatin capsule containing a commercial black grape extract three times a day for six weeks what results an amount of $0.21 \mathrm{~g}$ polyphenols per day and a total of $8.69 \mathrm{~g}$ total polyphenols after the 43 days. The study revealed that this preparation and doses contributed to a significant increase in plasma TAC and to an insignificant increase in SOD, as well as a lower GSH activity and reduce concentration in TBARS.

Taghizadeh et al. in a pilot study [90] tested the effect of a grape seed extract (GSE) on female volleyball players $(n=40)$. The dosage was $300 \mathrm{mg}$ of GSE twice a day for 8 weeks. No information about the polyphenol content was given but the results showed a significant rise in plasma GSH and a significant decrease in MDA. Besides, the players who received GSE exhibited a significant decrease serum insulin concentration. On the other hand, the administration of GSE had no significant effects on parameters like creatine kinase (CK) or TAC when compared with the administration of the placebo.

Another pilot study [92] is developed with an acute intake of $1000 \mathrm{mg}$ of a commercial grape supplement with pomegranate in two $500 \mathrm{mg}$ capsules $60 \mathrm{~min}$ before the start of an intense and continuous cycling exercise (Wingate test). The polyphenol content was $29 \mathrm{~g} / 100 \mathrm{~g}$ which results a dose of $0.29 \mathrm{~g}$ polyphenols. The study 
resulted in an increase in SOD, GSH and CAT activity, which remained stable until the end of the recovery period. The authors explained that in comparison with the placebo group the subjects supplemented showed no need to mobilize more antioxidant defenses before the exercise because and that the supplement probably contributed to spare oxidative homeostasis.

Finally, it must be pointed out the protocol [93] established for a pilot study that includes a product mix made of dried grapes with almonds and dried cranberries. No results are given but the authors describe the necessity of studying the F2-isoprostanes as a lipid peroxidation biomarker for oxidative stress.

\section{Conclusions}

Supplementation with grape polyphenols seems to have a positive effect against oxidative stress. These effects are dependent on the supplement dose, the length of the supplementation period or the polyphenolic profile (total polyphenol content and the distribution among polyphenolic families). Besides, according to several reports, it appears that the type and intensity of exercise can affect the response of the blood antioxidant defense system, just as the training status of the athlete, or the sport discipline. Considering the supplementation dosage in these studies it seems unlikely athletes would gain enough quantity of polyphenols from diet. Therefore, grape-based polyphenol concentrated products would be an interesting approach.

Moreover, inter-individual variability the age, sex, diet, environment factors, exercise protocols and even variability in gene expression could influence the polyphenols bioavailability and physiological responses to oxidative stress. Given the promising evidence, although still limited, more pilot studies on effect of grape polyphenols on the oxidative stress produced by sport should be conducted to determine the optimal concentration, dosage and effect on the oxidative stress for target athletes.

\footnotetext{
Abbreviations

NCD: Noncommunicable diseases; OS: Oxidative stress; RNS: Reactive nitrogen species; ROS: Reactive oxygen species; RONS: Reactive oxygen/ nitrogen species; DNA: Deoxyribonucleic acid; MDA: Malodialdehyde; TBARS: Thiobarbituric acid reactive substances; GC-MS: Gas ChromatographyMass Spectrometry; HPLC/GC-MS: High Performance Liquid Chromatography/Gas Chromatography-Mass Spectrometry; GC-tandem MS: GasChromatography-tandem Mass Spectrometry; ELISA: Enzyme-Linked ImmunoSorbent Assay; HPLC-ECD: High Performance Liquid Chromatography-Electrochemical Detection; 8-OHdG: 8-hydroxy-2'deoxyguanosine; TEAC: Trolox equivalent antioxidant capacity; FRAP: Ferric reducing ability of plasma; DPPH: 2, 2-diphenyl-1-picrylhydrazyl; ORAC: Oxygen radical absorbance capacity; SOD: Superoxide dismutase; CAT: Catalase; GPX: Glutathione peroxidase; $\mathrm{H}_{2} \mathrm{O}_{2}$ : Hydrogen peroxide; $\mathrm{H}_{2} \mathrm{O}$ : Water; $\mathrm{O}_{2}$ : Oxygen; GR: Glutathione reductase; G-6-PDH: Glucose-6phosphate dehydrogenase; NADPH: Reduced nicotinamide adenine dinucleotide phosphate; TMAO: Trimethylamine N-oxide; VO2max: Maximal oxygen uptake; GSH: Glutathione; TAC: Total antioxidant capacity; AGP: a1acid glycoprotein; CK: Creatine kinase; LDH: Lactate dehydrogenase; LDL: Low-density lipoproteins; HDL: High-density lipoproteins; UA: Uric acid; TA: Total antioxidant; NO: Nitric oxide; FPG: Fasting plasma glucose
}

\section{Acknowledgments}

Not applicable.

\section{Authors' contributions}

EE performed all background research, database searches, and wrote and edited the final manuscript. MCV and RMA provided guidance throughout the research, writing, submission process, editing of the final manuscript and approved the submitted version. The authors read and approved the final manuscript.

\section{Author's information}

EE is a senior scientist at TECNALIA, Basque Research and Technology Alliance (BRTA), PhD student with a master's degree in Chemistry and Genetics in Sport Nutrition at the University of the Basque Country (UPV/ EHU). MCV is the Head of the Food Area-Health Division at TECNALIA, Basque Research and Technology Alliance (BRTA). RMA is Professor at Analytical Chemistry Department, Faculty of Science and Technology, University of the Basque Country (UPV/EHU).

\section{Funding}

This research did not receive any specific grant from funding agencies in the public, commercial, or not-for-profit sectors.

\section{Availability of data and materials}

All data analyzed in this review are included in the cited articles.

\section{Ethics approval and consent to participate}

The studies examined in this review were approved by appropriate governing bodies for ethical research. No information regarding this issue with the pilot study developed by Skarpańska-Stejnborn, Basta, PilaczyńskaSzcześniak, \& Horoszkiewicz-Hassan, 2010.

\section{Consent for publication}

Not applicable.

\section{Competing interests}

The authors declare that they have no competing interests.

\section{Author details}

${ }^{1}$ TECNALIA, Basque Research and Technology Alliance (BRTA), Parque Tecnológico de Álava c/ Leonardo Da Vinci, 11, 01510 Miñano (Álava), Spain.

${ }^{2}$ Analytical Chemistry Department, Faculty of Science and Technology, University of the Basque Country (UPV/EHU), P.O. Box 644, 48080 Bilbao, Spain.

Received: 4 August 2020 Accepted: 30 November 2020

Published online: 07 January 2021

\section{References}

1. Physical activity [Internet]. [cited 2020 Jul 19]. Available from: https://www. who.int/health-topics/physical-activity\#tab=tab_1.

2. de Sousa CV, Sales MM, Rosa TS, Lewis JE, de Andrade RV, Simões HG. The antioxidant effect of exercise: a systematic review and meta-analysis. Sport Med. 2017:47(2):277-93.

3. Puterman E, Lin J, Blackburn E, O'Donovan A, Adler N, Epel E. The power of exercise: buffering the effect of chronic stress on telomere length. PLoS One. 2010;5(5):e10837.

4. Gordon B, Chen S, Durstine JL. The effects of exercise training on the traditional lipid profile and beyond. Curr Sport Med Rep. 2014;13(4):253-9.

5. Roque FR, Hernanz R, Salaices M. Exercise training and cardiometabolic diseases: focus on the vascular system. Curr Hypertens Rep. 2013;15(3): 204-14.

6. Pingitore A, Pace Pereira Lima G, Mastorci F, Quinones A, lervasi G, Vassalle C. Exercise and oxidative stress: potential effects of antioxidant dietary strategies in sports. Nutrition. 2015;31(7-8):916-22.

7. Devasagayam TPA, Tilak JC, Boloor KK, Sane KS, Ghaskadbi SS, Lele RD. Free radicals and antioxidants in human health: currant status and future prospects. J Assoc Physicians India. 2004;52:794-804.

8. Braakhuis A, Hopkins WG. Impact of dietary antioxidants on sport performance: a review. Sport Med. 2015;45(7):939-55. 
9. Pereira Panza V-S, Diefenthaeler F, da Silva EL. Benefits of dietary phytochemical supplementation on eccentric exercise-induced muscle damage: is including antioxidants enough? Nutrition. 2015;31(9):1072-82.

10. Barranco-Ruiz Y, Aragón-Vela J, Casals C, Martínez-Amat A, Casuso RA, Huertas JR. Control of antioxidant supplementation through interview is not appropriate in oxidative-stress sport studies: analytical confirmation should be required. Nutrition. 2017;33:278-84.

11. Nieman DC, Gillitt ND, Knab AM, Shanely RA, Pappan KL, Jin F, et al. Influence of a polyphenol-enriched protein powder on exercise-induced inflammation and oxidative stress in athletes: a randomized trial using a metabolomics approach. PLoS One. 2013;8(8):e72215.

12. Nieman DC, Stear SJ, Castell LM, Burke LM. A-Z of nutritional supplements: dietary supplements, sports nutrition foods and ergogenic aids for health and performance: part 15. Br J Sport Med. 2010;44:1202-5.

13. Bjørklund $\mathrm{G}$, Chirumbolo $\mathrm{S}$. Role of oxidative stress and antioxidants in daily nutrition and human health. Nutrition. 2017;33:311-21.

14. Fruit: world production by type 2018 | Statista [Internet]. [cited 2020 Jul 15]. Available from: https:/www.statista.com/statistics/264001/worldwideproduction-of-fruit-by-variety/.

15. International Organisation of Vine and Wine. 2016 World VitiViniculture Situation [lnternet]. 2016 [cited 2020 Jul 15]. Available from: http://www.oiv. int/public/medias/5029/world-vitiviniculture-situation-2016.pdf\%0A http:// www.oiv.int/public/medias/5479/oiv-en-bilan-2017.pdf.

16. García-Flores LA, Medina S, Gómez C, Wheelock CE, Cejuela R, Martínez-Sanz $J \mathrm{M}$, et al. Aronia-citrus juice (polyphenol-rich juice) intake and elite triathlon training: a lipidomic approach using representative oxylipins in urine. Food Funct. 2018;9:463-75.

17. Sureda A, Tejada S, Bibiloni MM, Tur JA, Pons A. Polyphenols: well beyond the antioxidant capacity: polyphenol supplementation and exercise-induced oxidative stress and inflammation. Curr Pharm Biotechnol. 2014;15:373-9.

18. De Ferrars RM, Czank C, Zhangm Q, Botting NP, Kroon PA, Cassidy A, et al. The pharmacokinetics of anthocyanins and their metabolites in humans. $\mathrm{Br}$ J Pharmacol. 2014;171:3268-82.

19. Czank C, Cassidy A, Zhang Q, Morrison DJ, Preston T, Kroon PA, et al. Human metabolism and elimination of the anthocyanin, cyaniding-3glucoside: a 13C-tracer study. Am J Clin Nutr. 2013;97:995-1003.

20. Williamson G, Clifford MN. Colonic metabolites of berry polyphenols: the missing link to biological activity? Br J Nutr. 2010;104:S48-66.

21. Warner EF, Zhang Q, Raheem KS, O'Hagan D, O'Connell MA, Kay CD. Common phenolic metabolites of flavonoids, but not their unmetabolized precursors, reduce the secretion of vascular cellular adhesion molecules by human endothelial cells. J Nutr. 2016;146:465-73.

22. Kay CD. Rethinking paradigms for studying mechanisms of action of plant bioactives. Nutr Bull. 2015;40:335-9.

23. Nieman DC, Mitmesser SH. Potential impact of nutrition on immune system recovery from heavy exertion: a metabolomics perspective. Nutrients. 2017; 9(5):1-23.

24. Nieman DC, Shanely RA, Gillit ND, Pappan KL, Lila MA. Serum metabolic signatures induced by a three-day intensified exercise period persist after 14 $\mathrm{h}$ of recovery in runners. J Proteome Res. 2013;12(10):4577-84.

25. Mach N, Fuster-Botella D. Endurance exercise and gut microbiota: A review. J Sport Heal Sci. 2017;6(2):179-97.

26. Kerksick CM, Wilborn CD, Roberts MD, Smith-Ryan A, Kleiner SM, Jäger R, et al. ISSN exercise \& sports nutrition review update: research \& recommendations. J Int Soc Sports Nutr. 2018;15(1):1-57.

27. Shankar K, Mehendale HM. Oxidative Stress. In: Wexler P, editor. Encyclopedia of Toxicology. Third Edit. Elsevier; 2014. p. 735-73. https://doi. org/10.1016/B978-0-12-386454-3.00345-6.

28. Lehmann R, Zhao X, Weigert C, Simon P, Fehrenbach E, Fritsche J, et al. Medium chain Acylcarnitines dominate the metabolite pattern in humans under moderate intensity exercise and support lipid oxidation. PLoS One. 2010:5:e11519.

29. Lewis GD, Farrell L, Wood MJ, Martinovic M, Arany Z, Rowe GC, et al. Metabolic Signatures of Exercise in Human Plasma. Sci Transl Med. 2010;2(33). https://doi. org/10.1126/scitranslmed.3001006.

30. Nieman DC, Gillitt ND, Sha W, Meaney MP, John C, Pappan KL, et al. Metabolomics-based analysis of banana and pear ingestion on exercise performance and recovery. J Proteome Res. 2015;14:5367-77.

31. Nieman DC, Gillitt ND, Henson DA, Wei Sha R, Andrew Shanely AM, Knab LC-K, et al. Bananas as an energy source during exercise: a metabolomics approach. PLoS One. 2012;7(5):e37479.
32. Nieman DC, Scherr J, Luo B, Meaney MP, Dréau D, Sha W, et al. Influence of pistachios on performance and exercise-induced inflammation, oxidative stress, immune dysfunction, and metabolite shifts in cyclists: a randomized, crossover trial. PLoS One. 2014;9(11):e113725.

33. Nieman DC, Sha W, Pappan KL. IL-6 linkage to exercise-induced shifts in lipid-related metabolites: A metabolomics-based analysis. J Proteome Res. 2017;16:970-7.

34. Nieman DC, Shanely RA, Luo B, Meaney MP, Dew DA, Pappan KL. Metabolomics approach to assessing plasma 13- and 9-hydroxyoctadecadienoic acid and linoleic acid metabolite responses to $75-\mathrm{km}$ cycling. Phys Act Inact. 2014;307(1):R68-74.

35. Powers SK, Radak Z, Ji LL. Exercise-induced oxidative stress: past, present and future. J Physiol. 2016;594(18):5081-92.

36. Dillard CJ, Litov RE, Savin WM, Dumelin EE, Tappel AL. Effects of exercise, vitamin $\mathrm{E}$, and ozone on pulmonary function and lipid peroxidation. J Appl Physiol. 1978;45:927-32.

37. Brady PS, Brady LJ, Ullrey DE. Selenium, vitamin E and the response to swimming stress in the rat. J Nutr. 1979;109:1103-9.

38. Powers SK, Jackson MJ. Exercise-induced oxidative stress: cellular mechanisms and impact on muscle force production. Physiol Rev. 2008;88: 1243-76.

39. McClung J, Deruisseau K, Whidden M, Van Remmen H, Richardson A, Song $W$, et al. Overexpression of antioxidant enzymes in diaphragm muscle does not alter contraction-induced fatigue or recovery. Exp Physiol. 2010;95(1): 222-31.

40. McClung JM, Judge AR, Powers SK, Yan Z. p38 MAPK links oxidative stress to autophagy-related gene expression in cachectic muscle wasting. Am J Physiol Cell Physiol. 2010;298(3):C542-9.

41. Powers SK, Duarte J, Kavazis AN, Talbert EE. Reactive oxygen species are signalling molecules for skeletal muscle adaptation. Exp Physiol. 2010;95:1-9.

42. Droge W. Free radicals in the physiological control of cell function. Physiol Rev. 2002;82:47-95.

43. Miller DM, Buettner GR, Aust SD. Transition metals as catalysts of "autoxidation" reactions. Free Radic Biol Med. 1990;8(1):95-108.

44. Bogdan C, Rollinghoff M, Diefenbach A. Reactive oxygen and reactive nitrogen intermediates in innate and specific immunity. Curr Opin Immunol. 2000;12(1):64-76.

45. Valko M, Leibfritz D, Moncol J, Cronin MT, Mazur M, Telser J. Free radicals and antioxidants in normal physiological functions and human disease. Int J Biochem Cell Biol. 2007:39(1):44-84.

46. McLeay Y, Stannard S, Houltham S, Starck C. Dietary thiols in exercise: oxidative stress defence, exercise performance, and adaptation. J Int Soc Sports Nutr 2017;14(1):1-8.

47. Mattson MP. Hormesis Defined. Ageing Res Rev. 2008;7(1):1-7.

48. Silveira LR, Pilegaard $H$, Kusuhara $K$, Curi R, Hellsten $Y$. The contraction induced increase in gene expression of peroxisome proliferator-activated receptor (PPAR)-gamma coactivator 1 alpha (PGC-1alpha), mitochondrial uncoupling protein 3 (UCP3) and hexokinase II (HKII) in primary rat skeletal muscle cells is dep. Biochim Biophys Acta 2006. 1763:969-76.

49. Zhou LZ, Johnson AP, Rando TA. NF kappa B and AP-1 mediate transcriptional responses to oxidative stress in skeletal muscle cells. Free Radic Biol Med. 2001;31:1405-16.

50. Handayaningsih A-E, lguchi $G$, Fukuoka $H$, Nishizawa $H$, Takahashi $M$, Yamamoto M, et al. Reactive oxygen species play an essential role in IGF-I signaling and IGF--induced myocyte hypertrophy in C2C12 myocytes. Endocrinol. 2011;152:912-21.

51. Balon TW, Nadler JL. Evidence that nitric oxide increases glucose transport in skeletal muscle. J Appl Physiol. 1997;82:359-63.

52. Steinbacher P, Eckl P. Impact of oxidative stress on exercising skeletal muscle. Biomolecules. 2015;5(2):356-77.

53. Marrocco I, Altieri F, Peluso I. Measurement and clinical significance of biomarkers of oxidative stress in humans. Oxidative Med Cell Longev. 2017;3. https://doi.org/10.1155/2017/6501046.

54. Merry TL, Mi R. Do antioxidant supplements interfere with skeletal muscle adaptation to exercise training? J Physiol. 2016;594(18):5135-47.

55. Ranchordas MK, Dawson JT, Russell M. Practical nutritional recovery strategies for elite soccer players when limited time separates repeated matches. J Int Soc Sports Nutr. 2017;14(1):1-14.

56. Yfanti C, Deli CK, Georgakouli K, Fatouros I, Jamurtas AZ. Sport nutrition, redox homeostasis and toxicity in sport performance. Curr Opin Toxicol. 2020;13(February 2019):45-67. 
57. Finaud J, Lac G, Filaire E. Oxidative stress. Sport Med. 2006;36(4):327-58.

58. Rousseau I, Margaritis AS. Does physical exercise modify antioxidant requirements? Nutr Res Rev. 2008;21(1):3-12.

59. Powers SK, Lennon SL. Analysis of cellular responses to free radicals: focus on exercise and skeletal muscle. Proc Nutr Soc. 2000;58:1025-33.

60. Tiidus PM, Pushkarenko J, Houston ME. Lack of antioxidant adaptation to shortterm aerobic training in human muscle. Am J Physiol. 1996;271:R832-6.

61. Jenkins RR, Goldfarb A. Introduction: oxidant stress, aging and exercise. Med Sci Sport Exerc. 1993;25(2):210-2.

62. Antunes F, Derick H, Cadenas E. Relative contributions of heart mitochondria glutathione peroxidase and catalase to $\mathrm{H} 2 \mathrm{O} 2$ detoxification in in vivo conditions. Free Radic Biol Med. 2002;33(9):1260-7.

63. Waring WS, Convery A, Mishra V, Shenkin A, Webb DJ, Maxwell SR. Uric acid reduces exercise-induced oxidative stress in healthy adults. Clin Sci. 2003; 105(4):425-30

64. Groussard C, Rannou-Bekono F, Machefer G, Chevanne M, Vincent S, Sergent $\mathrm{O}$, et al. Changes in blood lipid peroxidation markers and antioxidants after a single sprint anaerobic exercise. Eur J Appl Physiol. 2003; 89(1):14-20.

65. Fisher-Wellman K, Bloomer RJ. Acute exercise and oxidative stress: a 30 year history. Dyn Med. 2009;8(1):1-25.

66. Sacheck JM, Blumberg JB. Role of vitamin E and oxidative stress in exercise. Nutrition. 2001:17(10):809-14.

67. Kurutas EB. The importance of antioxidants which play the role in cellular response against oxidative / nitrosative stress : current state. Nutr J. 2015; 15(71):1-22.

68. Milner JA. Reducing the risk of cancer. In: Goldberg I, editor. Functional foods: designer foods, Pharmafoods, Nutraceuticals. New York: Chapman \& Hall; 1994. p. 39-70.

69. Duthie GG, Brown KM. Reducing the risk of cardiovascular disease. In: Goldberg I, editor. Functional foods: designer foods, Pharmafoods, Nutraceuticals. New York: Chapman \& Hall; 1994. p. 19-38.

70. Harborne JB, Williams CA. Advances in flavonoid research since 1992. Phytochemistry. 2000:55:481-504.

71. Bravo L. Polyphenols: chemistry, dietary sources, metabolism, and nutritional significance. Nutr Rev. 1998:56:317-33.

72. Cheynier V. Polyphenols in foods are more complex than often thought. Am J Clin Nutr. 2005;81:223S-9S.

73. Birt DF, Jeffery E. Nutrient information of flavonoids. Adv Nutr. 2013;1:576-7.

74. Tsao R. Chemistry and biochemistry of dietary polyphenols. Nutrients. 2010; 2:1231-46.

75. Mishra A, Kumar S, Pandey AK. Scientific validation of the medicinal efficacy of Tinospora cordifolia. Sci World J 2013;2013:8.

76. Halliwell B, Gutteridge JMC. Free radicals in biology and medicine. Oxford: Oxford University Press; 2015.

77. Parker TL, Wang X-H, Pazmiño J, Engeseth NJ. Antioxidant capacity and phenolic content of grapes, sun-dried raisins, and golden raisins and their effect on ex vivo serum antioxidant capacity. J Agric Food Chem. 2007;55: 8472-7

78. Annunziata G, Maisto M, Schisano C, Ciampaglia R, Narciso V, Hassan STS, et al. Effect of grape pomace polyphenols with or without pectin on TMAO serum levels assessed by LC/MS-based assay: A preliminary clinical study on overweight/obese subjects. Front Pharmacol. 2019;10:575.

79. Annunziata G, Maisto M, Schisano C, Ciampaglia R, Narciso V, Tenore GC, et al. Effects of grape pomace polyphenolic extract (Taurisolo ${ }^{\oplus}$ ) in reducing TMAO serum levels in humans: preliminary results from a randomized, placebo-controlled, cross-over study. Nutrients. 2019;11(1):139.

80. Annunziata G, Jimenez-García M, Tejada S, Moranta D, Arnone A, Ciampaglia $R$, et al. Grape polyphenols ameliorate muscle decline reducing oxidative stress and oxidative damage in aged rats. Nutrients. 2020;12(5):1280

81. Morillas-Ruiz J, Zafrilla P, Almar M, Cuevas MJ, López FJ, Abellán P, et al. The effects of an antioxidant-supplemented beverage on exercise-induced oxidative stress: results from a placebo-controlled double-blind study in cyclists. Eur J Appl Physiol. 2005;95(5-6):543-9.

82. Gonçalves MC, Bezerra FF, de Eleutherio ECA, Bouskela E, Koury J. Organic grape juice intake improves functional capillary density and postocclusive reactive hyperemia in triathletes. Clinics. 2011;66(9):1537-41.

83. Silvestre JC, Juzwiak CR, Gollücke APB, Dourado VZ, D'Almeida V. Acute effect of a grape concentrate intake on oxidative stress markers in triathletes. Rev Bras Cineantropometria Desempenho Hum. 2014;16(5): 533-44.
84. Toscano LT, Tavares RL, Toscano LT, da Silva CSO, de Almeida AEM, Biasoto ACT, et al. Potential ergogenic activity of grape juice in runners. Appl Physiol Nutr Metab. 2015;40(9):899-906.

85. Tavares-Toscano L, Sérgio-Silva A, Tavares-Toscano L, Leite-Tavares R, Camarão-Telles-Biasoto A, Surama-Oliveira-da-Silva C, et al. Phenolics from purple grape juice increase serum antioxidant status and improve lipid profile and blood pressure in healthy adults under intense physical training. Junct Foods. 2017;33:419-24.

86. Kedare SB, Singh RP. Genesis and development of DPPH method of antioxidant assay. J Food Sci Technol. 2011;48(4):412-22.

87. de Lima Tavares Toscano L, Silva AS, ACL d F, BRV d S, EJB d AF, da Silveira Costa $\mathrm{M}$, et al. A single dose of purple grape juice improves physical performance and antioxidant activity in runners: a randomized, crossover, double-blind, placebo study. Eur J Nutr. 2019:1-11.

88. Sadowska-Krępa E, Barbara Kłapcińska E, Kimsa RK. Effects of supplemetation with red grape skin polyphenolic extract and interval swimming test on the blood antioxidant status in healthy men. Med Sport. 2008;12(1):1-7.

89. Skarpańska-Stejnborn A, Basta P, Pilaczyńska-Szczesniak Ł, HoroszkiewiczHassan M. Blackgrape extract supplementation attenuates blood oxidative stress in response to acute exercise. Biol Sport. 2010;27(1):41-6.

90. Taghizadeh M, Malekian E, Memarzadeh MR, Mohammadi AA, Asemi Z. Grape seed extract supplementation and the effects on the biomarkers of oxidative stress and metabolic profiles in female volleyball players: A randomized, double-blind, placebo-controlled clinical trial. Iran Red Crescent Med J. 2016;18(9):e31314.

91. Lafay S, Jan C, Nardon K, Lemaire B, Ibarra A, Roller M, et al. Grape extract improves antioxidant status and physical performance in elite male athletes. J Sports Sci Med. 2009;8(3):468-80.

92. Cases J, Romain C, Marín-Pagán C, Chung LH, Rubio-Pérez JM, Laurent C, et al. Supplementation with a polyphenol-rich extract, Perfload ${ }^{\oplus}$, improves physical performance during high-intensity exercise: A randomized, double blind, crossover trial. Nutrients. 2017;9(4):421.

93. D'unienville NMA, Hill A, Coates A, Yandell C, Nelson M, Buckley J. Effects of almond, dried grape and dried cranberry consumption on endurance exercise performance, recovery and psychomotor speed: protocol of a randomised controlled trial. BMJ Open Sport Exerc Med. 2019;5:e000560

\section{Publisher's Note}

Springer Nature remains neutral with regard to jurisdictional claims in published maps and institutional affiliations.
Ready to submit your research? Choose BMC and benefit from:

- fast, convenient online submission

- thorough peer review by experienced researchers in your field

- rapid publication on acceptance

- support for research data, including large and complex data types

- gold Open Access which fosters wider collaboration and increased citations

- maximum visibility for your research: over $100 \mathrm{M}$ website views per year

At $\mathrm{BMC}$, research is always in progress.

Learn more biomedcentral.com/submissions 